\title{
Article \\ Upper Gastrointestinal Lesions during Endoscopy Surveillance in Patients with Lynch Syndrome: A Multicentre Cohort Study
}

\author{
Romain Chautard ${ }^{1, *(\mathbb{D})}$, David Malka ${ }^{2} \mathbb{D}$, Elia Samaha ${ }^{3}$, David Tougeron $\left.{ }^{4} \mathbb{(}\right)$, Didier Barbereau ${ }^{1}$, Olivier Caron ${ }^{2}$, \\ Gabriel Rahmi ${ }^{3}$, Thierry Barrioz ${ }^{4}$, Christophe Cellier ${ }^{3}$, Sandrine Feau ${ }^{1}$ and Thierry Lecomte ${ }^{1, *}$
}

1 Department of Hepatogastroenterology and Digestive Oncology, Trousseau University Hospital, CHU de Tours, CEDEX 09, 37044 Tours, France; d.barbereaupro@orange.fr (D.B.); sandrine.feau@hotmail.fr (S.F.)

2 Gastrointestinal Oncology Unit, Department of Oncologic Medicine, Institut Gustave Roussy, Université Paris Sud, 94805 Villejuif, France; david.malka@gustaveroussy.fr (D.M.); olivier.caron@igr.fr (O.C.)

3 Department of Gastroenterology, European Georges Pompidou Hospital, Assistance Publique Hôpitaux de Paris, 75015 Paris, France; elia.samaha@aphp.fr (E.S.); gabriel.rahmi@egp.aphp.fr (G.R.); christophe.cellier@egp.aphp.fr (C.C.)

4 Department of Gastroenterology, Poitiers University Hospital, 86021 Poitiers, France; david.tougeron@chu-poitiers.fr (D.T.); t.barrioz@chu-poitiers.fr (T.B.)

* Correspondence: romain.chautard@gmail.com (R.C.); thierry.lecomte@med.univ-tours.fr (T.L.); Tel.: +33-2-47-47-59-00 (R.C. \& T.L.)

Citation: Chautard, R.; Malka, D.; Samaha, E.; Tougeron, D.; Barbereau, D.; Caron, O.; Rahmi, G.; Barrioz, T.; Cellier, C.; Feau, S.; et al. Upper Gastrointestinal Lesions during Endoscopy Surveillance in Patients with Lynch Syndrome: A Multicentre Cohort Study. Cancers 2021, 13, 1657. https://doi.org/10.3390/cancers 13071657

Academic Editors: Paola Izzo and Francesca Duraturo

Received: 4 January 2021

Accepted: 28 March 2021

Published: 1 April 2021

Publisher's Note: MDPI stays neutral with regard to jurisdictional claims in published maps and institutional affiliations.

Copyright: (c) 2021 by the authors. Licensee MDPI, Basel, Switzerland. This article is an open access article distributed under the terms and conditions of the Creative Commons Attribution (CC BY) license (https:/ / creativecommons.org/licenses/by/ $4.0 /)$.
Simple Summary: Patients with Lynch syndrome are at increased risk of upper gastrointestinal cancer. Recommendations for upper gastrointestinal endoscopy screening vary widely with limited data supporting effectiveness. The aim of our study was to investigate yields of upper gastrointestinal endoscopy screening in a large multicentre cohort of 172 Lynch syndrome mutation carriers. In our study, upper gastrointestinal endoscopy surveillance detects frequent neoplastic lesions particularly after the age of 40 years. Ours results suggest that Lynch patients should be considered for upper gastrointestinal endoscopic and Helicobacter pylori screening.

Abstract: Background: Patients with Lynch syndrome are at increased risk of gastric and duodenal cancer. Upper gastrointestinal endoscopy surveillance is generally proposed, even though little data are available on upper gastrointestinal endoscopy in these patients. The aim of this retrospective study was to evaluate the prevalence and incidence of gastrointestinal lesions following upper gastrointestinal endoscopy examination in Lynch patients. Methods: A large, multicentre cohort of 172 patients with a proven germline mutation in one of the mismatch repair genes and at least one documented upper gastrointestinal endoscopy screening was assessed. Detailed information was collected on upper gastrointestinal endoscopy findings and the outcome of endoscopic follow-up. Results: Seventy neoplastic gastrointestinal lesions were diagnosed in 45 patients (26\%) out of the 172 patients included. The median age at diagnosis of upper gastrointestinal lesions was 54 years. The prevalence of cancer at initial upper gastrointestinal endoscopy was $5 \%$ and the prevalence of precancerous lesions was $12 \%$. Upper gastrointestinal lesions were more frequent after 40 years of age $(p<0.001)$. Helicobacter pylori infection was associated with an increased prevalence of gastric, but not duodenal, lesions $(p<0.001)$. Conclusions: Neoplastic upper gastrointestinal lesions are frequent in patients with Lynch syndrome, especially in those over 40 years of age. The results of our study suggest that Lynch patients should be considered for upper gastrointestinal endoscopic and Helicobacter pylori screening.

Keywords: Lynch syndrome; upper gastrointestinal endoscopy; gastric cancer; duodenal cancer; screening; Helicobacter pylori 


\section{Introduction}

Lynch syndrome (also known as hereditary nonpolyposis colorectal cancer (HNPCC) syndrome) is an autosomal dominant syndrome involving germline mutations in genes that encode DNA mismatch repair (MMR) proteins [1]. Inactivation of the DNA MMR genes (MLH1, MSH2, or more rarely MSH6 and PMS2) predisposes carriers to multiple malignancies, including early-onset colorectal and endometrial cancer, or less frequently ovarian, small bowel, urothelium, biliary tract, and gastric cancers [1,2]. Lynch syndrome is responsible for approximately $2 \%$ of all diagnosed cases of colorectal cancer [3]. Individuals with Lynch syndrome have about a $50-80 \%$ lifetime risk of colon cancer, and women with Lynch syndrome have a $60 \%$ lifetime risk of endometrial cancer [4].

Gastric cancer has been reported to be the third or fourth most common extracolonic cancer in Lynch syndrome. The cumulative lifetime risk of gastric cancer in Lynch syndrome (LS) is reported to be varying from $2 \%$ to $8 \%$ [2,5-7]. This risk is highest in older patients and those with the pathogenic MSH2 and MLH1 variants [7]. Even though the relative risk of developing small bowel carcinoma in Lynch syndrome is extremely high (over $100)$, the lifetime risk remains relatively low $(2-8 \%)$, consisting of duodenal carcinomas in approximately half of the cases [6,8-11]. However, a recent large study reported that the estimated cumulative risk for gastric cancer and small bowel cancer is less than $1 \%$ at 70 years, which is lower than previously reported [8].

On the basis of observational studies, colonoscopy screening has been shown to be effective in reducing the incidence and mortality of colorectal cancer among MMR mutation carriers [12]. Colonoscopy screening is recommended every 1 to 2 years, beginning at age 20-25, or 5 years younger than the earliest-onset cancer recorded among the affected members in the family $[13,14]$. Although few surveillance data for gastric or small-bowel cancer are available, screening individuals with Lynch syndrome using upper gastrointestinal endoscopy (UGE) is recommended by several expert consensus statements, but it remains controversial [13-18]. Helicobacter pylori (H. pylori) infection is associated with increased risk of gastric cancer $[19,20]$. H. pylori eradication prevents gastric cancer and screening is recommended in patients at high risk of gastric cancer [21]. The sequence of events from $H$. pylori infection, through atrophic chronic gastritis with metaplasia to dysplasia, is considered to be the precursor cascade of gastric cancer, especially of an intestinal type [20]. In Lynch syndrome, the intestinal type seems the most frequent form of gastric cancer [5,22].

The goal of UGE is to detect precancerous lesions at an early curable stage and to detect $H$. pylori infection. Only few studies have evaluated the prevalence of $H$. pylori infection and the effectiveness of surveillance for gastric cancer in individuals with Lynch syndrome [23-27]. Therefore, the utility and optimal modalities for screening for gastric and duodenal cancers in individuals with Lynch syndrome remain undefined. In spite of these uncertainties, guidelines from numerous professional societies recommend consideration of UEG screening with esophagogastroduodenoscopy and testing for H. pylori for all individuals with LS (Table 1).

Recent guidelines recommend that UGE surveillance in Lynch syndrome should only be performed in the context of a clinical trial [14]. However, there is a general consensus on the need to screen $\mathrm{H}$. pylori in patients with Lynch syndrome and subsequent eradication therapy. We report here the incidence and prevalence of gastrointestinal lesions and $H$. pylori infection in a large, retrospective, multicentre cohort of individuals with Lynch syndrome. 
Table 1. Current upper gastrointestinal screening guidelines from various medical societies in Lynch syndrome.

\begin{tabular}{|c|c|}
\hline Medical Society & Guidelines \\
\hline $\begin{array}{l}\text { United States Multi-Society Task } \\
\text { Force [13] }\end{array}$ & $\begin{array}{l}\text { - Consider baseline upper gastrointestinal endoscopy with biopsy } \\
\text { for } H \text { pylori for all Lynch syndrome carriers at age } 30-35 \\
\text { - Consider ongoing surveillance every 2-3 years based on } \\
\text { individual patient risk factors }\end{array}$ \\
\hline $\begin{array}{l}\text { American College of } \\
\text { Gastroenterology [15] }\end{array}$ & $\begin{array}{l}\text { - Consider baseline upper gastrointestinal endoscopy with biopsy } \\
\text { for } H \text {. pylori for all Lynch syndrome carriers at age 30-35 } \\
\text { - Consider ongoing surveillance every 3-5 years for Lynch } \\
\text { syndrome carriers with a family history of gastric or } \\
\text { duodenal cancer }\end{array}$ \\
\hline $\begin{array}{l}\text { American Society of Clinical } \\
\text { Oncology [16] }\end{array}$ & $\begin{array}{l}\text { - } \quad \text { Consider upper gastrointestinal endoscopy surveillance every } \\
\text { 1-3 years in high-risk subsets of Lynch syndrome carriers } \\
\text { - } \quad \text { Test all Lynch syndrome carriers for H. pylori }\end{array}$ \\
\hline $\begin{array}{c}\text { European Society of Digestive } \\
\text { Oncology and European Society for Medical Oncology [17] }\end{array}$ & $\begin{array}{l}\text { - Upper gastrointestinal endoscopy should be performed } \\
\text { regularly every 1-2 years in mutation carriers starting no later } \\
\text { than the age of } 30 \text { years, regardless of the family history } \\
\text { - } \quad \text { Test all Lynch syndrome carriers for H. pylori }\end{array}$ \\
\hline $\begin{array}{l}\text { British Society of Gastroenterology and Association of } \\
\text { Coloproctology of Great Britain and Ireland and United } \\
\text { Kingdom Cancer Genetics Group [18] }\end{array}$ & $\begin{array}{l}\text { - We recommend that gastric or small bowel surveillance in } \\
\text { Lynch syndrome patients is only performed in the context of a } \\
\text { clinical trial. } \\
\text { We recommend screening for H. pylori in patients with Lynch } \\
\text { syndrome and subsequent eradication therapy if indicated. }\end{array}$ \\
\hline $\begin{array}{l}\text { European Hereditary Tumour Group and European } \\
\text { Society of Coloproctology [14] }\end{array}$ & $\begin{array}{l}\text { - Consensus was not achieved for the statement "Surveillance for } \\
\text { other cancers (than colorectal, endometrial and ovarian) should } \\
\text { not be offered". }\end{array}$ \\
\hline
\end{tabular}

\section{Patients and Methods}

\subsection{Study Design}

Individuals were enrolled at four tertiary-care centres experienced in Lynch syndrome management. Individuals were eligible for this study if they had a proven pathological germline mutation in one of the MMR genes (MSH2, MLH1, MSH6, or PMS2) and with at least one UGE screening. The primary endpoint was the proportion of abnormal UGE among the screened patients. At our centres, we routinely perform UGE surveillance in Lynch syndrome. Experienced endoscopists performed UEG screening with standard adult endoscopes. Systematic biopsy was not performed during the UEG screening and was left to the discretion of the endoscopist. This study was reviewed and approved by the local Ethics Committee (Comité de Protection des Personnes, Tours, France, Number 20021 004).

\subsection{Subjects and Data Collection}

Patients were included and data were recorded by each centre retrospectively and anonymously between December 2009 and May 2011. The data collected included gender, date of birth, previous history of cancer, family history of gastric and duodenal cancers, type of MMR gene mutation, number of UGEs during the follow-up, interval between UGE surveillance screens, the endoscopic and histopathological findings in the upper gastrointestinal tract, and H. pylori status.

Gastritis, atrophy, intestinal metaplasia, dysplasia, and H. pylori infection were evaluated according to the Sydney system classification [28]. Precancerous gastric lesions were defined as atrophic gastritis, intestinal metaplasia, or dysplasia. The H. pylori status was determined by histology or urea breath test.

\subsection{Statistical Analysis}

The prevalence of lesions was evaluated from the records of the first available UGE. For the calculation of incidence rates, all the patients included were considered to be at risk. The number of precancerous lesions or cancers that developed after the first UGE and the 
person-years of follow-up of each patient were used as the numerator and denominator, respectively, for estimating the incidence of precancerous lesions and cancers. The statistical associations between upper gastrointestinal lesion prevalence and MMR mutation, $H$. pylori infection, and age were analysed using the $\chi^{2}$ test. The incidence of gastrointestinal lesions was calculated for several different age classes: <30 years, 30-39 years, 40-49 years, 50-59 years, and $>60$ years. Statistical analyses were performed with Stata 9.0 statistical software (College Station, TX, USA). All tests were two-sided, and $p$ values below 0.05 were considered to be statistically significant.

\section{Results}

\subsection{Baseline Characteristics and Cumulative Endoscopic and Histopathological Findings}

A total of 172 individuals undergoing this screening programme were evaluated. Their baseline characteristics are described in Table 2. The spectrum of endoscopic findings in our cohort is given in Table 3. One hundred and seventeen patients $(68 \%)$ had undergone gastric biopsies during their initial endoscopic examination. Overall, 45 (26\%) of the 172 patients were found to have precancerous lesions or cancer, 20 (44\%) of whom had more than one lesion. Seventy neoplastic (precancerous or cancerous) upper gastrointestinal tract lesions (gastric, $n=59$; duodenal, $n=11$ ) were diagnosed. The dysplastic lesions and cancers were located in the stomach in $52 \%$ of cases and in the duodenum in the other $48 \%$ of cases. Most of the gastric lesions were distal $(60 \%)$, including four of the five gastric cancers, which were located in the antrum. The cumulative frequencies of intestinal metaplasia, atrophic gastritis, dysplasia, and stomach cancer were $15 \%, 12 \%, 4 \%$, and 3\%, respectively. The cumulative frequencies of duodenal dysplasia and cancer were $4 \%$ and $3 \%$, respectively.

Table 2. Baseline patient characteristics.

\begin{tabular}{cc}
\hline Characteristic & $\begin{array}{c}\text { Patients } \boldsymbol{n} \mathbf{( \% )} \\
(\boldsymbol{n}=\mathbf{1 7 2})\end{array}$ \\
\hline Sex, male/ female & $66 / 106(38 / 62)$ \\
\hline MMR * genes mutation \\
MLH1 \\
MSH2 \\
PSH6 & $63(37)$ \\
\hline Family history of gastric cancer & $82(48)$ \\
Family history of duodenal cancer & $26(15)$ \\
\hline Personal history of cancer & $1(<1)$ \\
\hline Median age at diagnosis of first cancer (range) & $26(15)$ \\
\hline Personal history of cancers & $8(5)$ \\
Colorectal cancer & $84(49)$ \\
Endometrial cancer & $41(14-61)$ \\
Urinary tract cancer & $73(42)$ \\
Ovarian cancer & $15(9)$ \\
\hline
\end{tabular}

${ }^{*}$ MMR: Mismatch repair.

\subsection{Initial Upper Gastrointestinal Endoscopy Findings}

The median age of patients at the first UGE was 44 years (range, 14-75). The initial UGE was performed for gastrointestinal symptoms in 24 patients (14\%) detected during colonoscopy screening. Twenty-six of the 172 patients $(15 \%)$ had precancerous lesions ( $n=21,12 \%)$ and/or cancer $(n=7,4 \%$ ) at their first endoscopy. Of the seven patients with gastric or duodenal cancer at initial UGE, five (63\%) had digestive symptoms. 
Table 3. Cumulative endoscopic findings in our study population.

\begin{tabular}{|c|c|c|c|c|}
\hline \multicolumn{2}{|c|}{ Endoscopic Findings } & $\begin{array}{l}\text { At First } \\
\text { UGE }(n)\end{array}$ & $\begin{array}{l}\text { At Later } \\
\text { UGE (n) }\end{array}$ & $\begin{array}{r}\text { Total Patients: } \\
n(\% \text { of } n=172)\end{array}$ \\
\hline \multirow{3}{*}{ Cancers } & \multirow{3}{*}{$\begin{array}{c}\text { Gastric adenocarcinoma } \\
\text { Duodenal adenocarcinoma } \\
\text { Duodenal non-Hodgkin } \\
\text { lymphoma }\end{array}$} & 4 & 1 & $5(3)$ \\
\hline & & 4 & 1 & $5(3)$ \\
\hline & & 0 & 1 & $1(<1)$ \\
\hline \multirow{4}{*}{$\begin{array}{l}\text { Gastric } \\
\text { polyps }\end{array}$} & Adenomatous polyps & 1 & 3 & $4(2)$ \\
\hline & Low-grade dysplasia & 1 & 2 & $3(2)$ \\
\hline & High-grade dysplasia & 0 & 1 & $1(<1)$ \\
\hline & Fundic gland polyps & 9 & 4 & $13(8)$ \\
\hline \multirow{5}{*}{$\begin{array}{l}\text { Duodenal } \\
\text { polyps }\end{array}$} & Adenomatous polyps & 1 & 5 & $6(2)$ \\
\hline & Low-grade dysplasia & 1 & 4 & $5(3)$ \\
\hline & High-grade dysplasia & 0 & 1 & $1(<1)$ \\
\hline & Hyperplasic polyps & 1 & 0 & $1(<1)$ \\
\hline & Inflammatory polyps & 1 & 0 & $1(<1)$ \\
\hline \multirow{4}{*}{$\begin{array}{l}\text { Other gastro- } \\
\text { duodenal } \\
\text { lesions }\end{array}$} & Atrophic gastritis & 8 & 13 & $21(12)$ \\
\hline & Intestinal metaplasia & 11 & 15 & $26(15)$ \\
\hline & Low-grade dysplasia & 1 & 1 & $2(1)$ \\
\hline & High-grade dysplasia & 0 & 1 & $1(<1)$ \\
\hline
\end{tabular}

\subsection{Endoscopic Follow-Up and Incidence of Upper Gastrointestinal Lesions}

Follow-up UGE was performed in 109 of the patients $(63 \%)$ included in this study. The median number of endoscopy procedures per patient was 3 (range, 2-10). The frequency of endoscopic surveillance was 1-2 years for 80 patients (73\%), 3-4 years for 24 patients $(22 \%)$, and 5 years or more for five patients (4.5\%). Among the 63 patients who had undergone only one upper gastrointestinal endoscopy, 56 were included in the study less than 2 years after their first endoscopy, one patient had undergone total gastrectomy for gastric cancer, and only six patients had no gastrointestinal follow-up. Gastric biopsies were systematically included in the endoscopic examinations in 60 patients (55\%) who underwent follow-up UGE.

After a mean follow-up of 5 years (range, 1-19), 19 patients were diagnosed with intestinal metaplasia $(n=15)$, gastric $(n=5)$ or duodenal $(n=5)$ dysplasia, atrophic gastritis $(n=13)$, gastric cancer $(n=1)$, or duodenal cancer $(n=1)$ after a median interval of 5 years since the initial UGE (range, 1-16). The incidence of gastric metaplasia, atrophic gastritis, gastric dysplasia, duodenal dysplasia, gastric cancer, and duodenal cancer was 26.0, 22.5, $8.7,8.7,1.7$, and 1.7 per 1000 person-years, respectively. Of the 95 patients with normal findings at the initial UGE, none had cancer, and precancerous lesions were found in $19(20 \%)$ of them during follow-up examinations. Of the ten patients with precancerous lesions at the initial examination, two $(20 \%)$ developed cancer during follow-up. Seventysix patients $(70 \%)$ did not develop any precancerous lesion or cancer during follow-up.

\subsection{Association of Upper Gastrointestinal Lesions with Baseline Characteristics}

The incidences of precancerous and cancerous lesions by age group are presented in Figure 1. The median age of patients with precancerous lesions was 53 years (range, 23-71). The incidence of precancerous or cancerous upper gastrointestinal lesions was $6 \%$ among patients under 30 years of age, $14 \%$ among patients aged between 30 and 39 years, $27 \%$ among patients aged between 40 and 49 years, $53 \%$ among patients aged between 50 and 59 years, and $60 \%$ among patients aged between 60 and 69 years. The incidence of precancerous and cancerous upper gastrointestinal lesions was higher in patients over 40 years of age than in their younger counterparts $(43 \%$ vs. $10 \%, p<0.001)$.

The prevalence of precancerous and cancerous upper gastrointestinal lesions in MHL1, MSH2, and MSH6 mutation carriers are presented in Figure 2. The only patient with a PMS2 mutation had no lesion. Patients with an MSH6 mutation had more intestinal 
metaplasia (9/26) than patients with an MSH2 (9/82) or MLH1 (8/63) mutation $(p=0.003)$. There was no statistically significant difference in the prevalence of other lesions; none of the patients with an MSH6 mutation had upper gastrointestinal cancer.

No significant association was found between cancerous and precancerous lesions of the upper gastrointestinal tract and sex or family history of upper gastrointestinal cancer. Of the 26 patients with a family history of gastric cancer, six $(23 \%)$ had gastric cancerous or precancerous lesions. Only one patient with gastric cancer had a family history of gastric cancer.

More specifically, of the 172 patients undergoing the screening programme, 10 (5.8\%) had an upper gastrointestinal cancer. They were mainly males (66\%) with a median age of 49 years (range, 14-66). All cancers were adenocarcinomas without independent cells (90\%), except for one duodenal non-Hodgkin lymphoma. The characteristics of these adenocarcinomas are described in Table 4. There were five adenocarcinomas for each duodenal and gastric localization. One patient had a synchronous gastric and duodenal cancer; he carried an $\mathrm{MSH} 2$ mutation and was treated with best supportive care. There were no significant differences in cancer characteristics between patients with $M L H 1$ and MSH2 mutations even though there were numerically more duodenal adenocarcinomas in patients with an MLH1 mutation (3 vs. 2). No cancer was detected in patients with MSH6 or PMS2 mutations. Seven patients had their cancer diagnosed at the initial UGE. Of these seven, five $(63 \%)$ had digestive symptoms. All adenocarcinomas but one were surgically removed, including two after the initial mucosectomy. All adenocarcinomas but one had no distant metastasis and only three (30\%) had lymph nodes spreading. Helicobacter pylori infection was confirmed by biopsy in only two patients $(22 \%)$. These patients had both a localized gastric adenocarcinoma without lymph node spreading as well as an associated atrophic gastritis. Two patients had personal histories of endometrial cancer, including one carrying an $\mathrm{MSH} 2$ mutation and with a personal history of colorectal and urinary tract cancers.

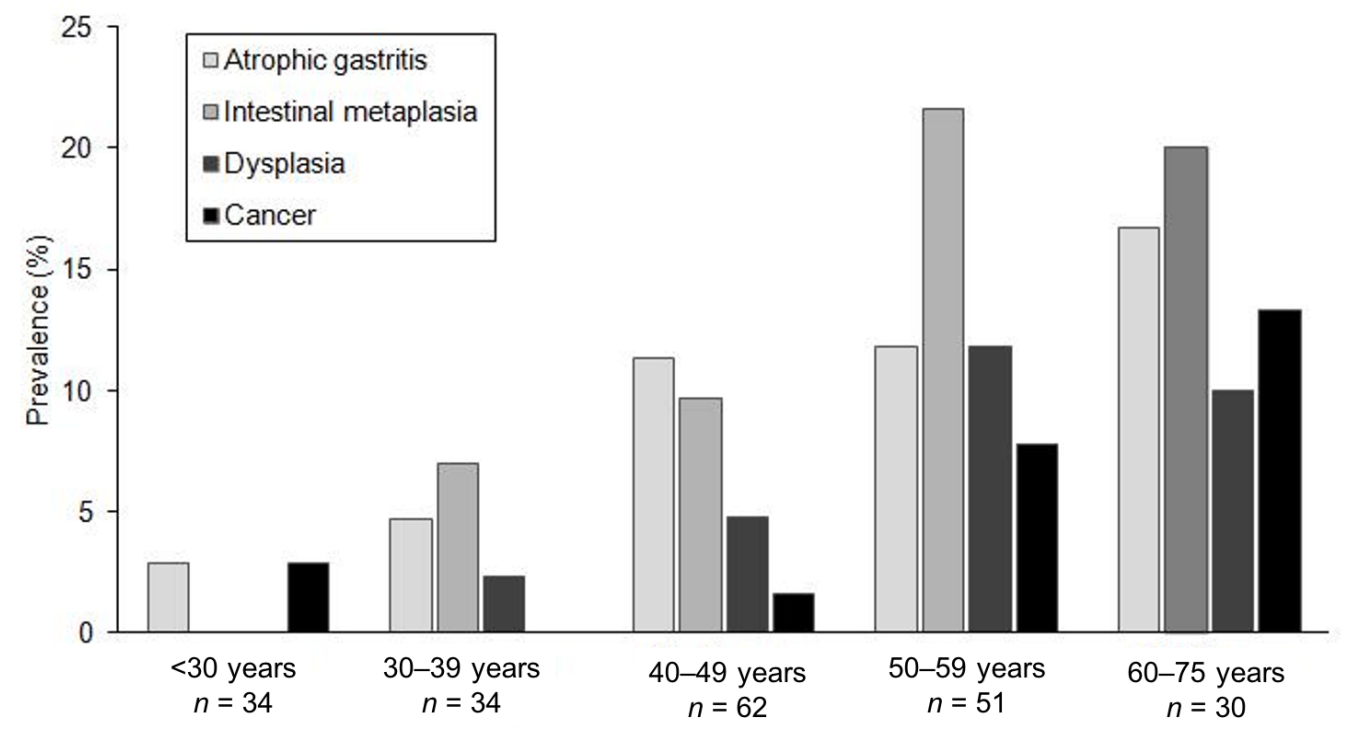

Figure 1. Incidence of gastric precancerous lesions and cancer by age group. 


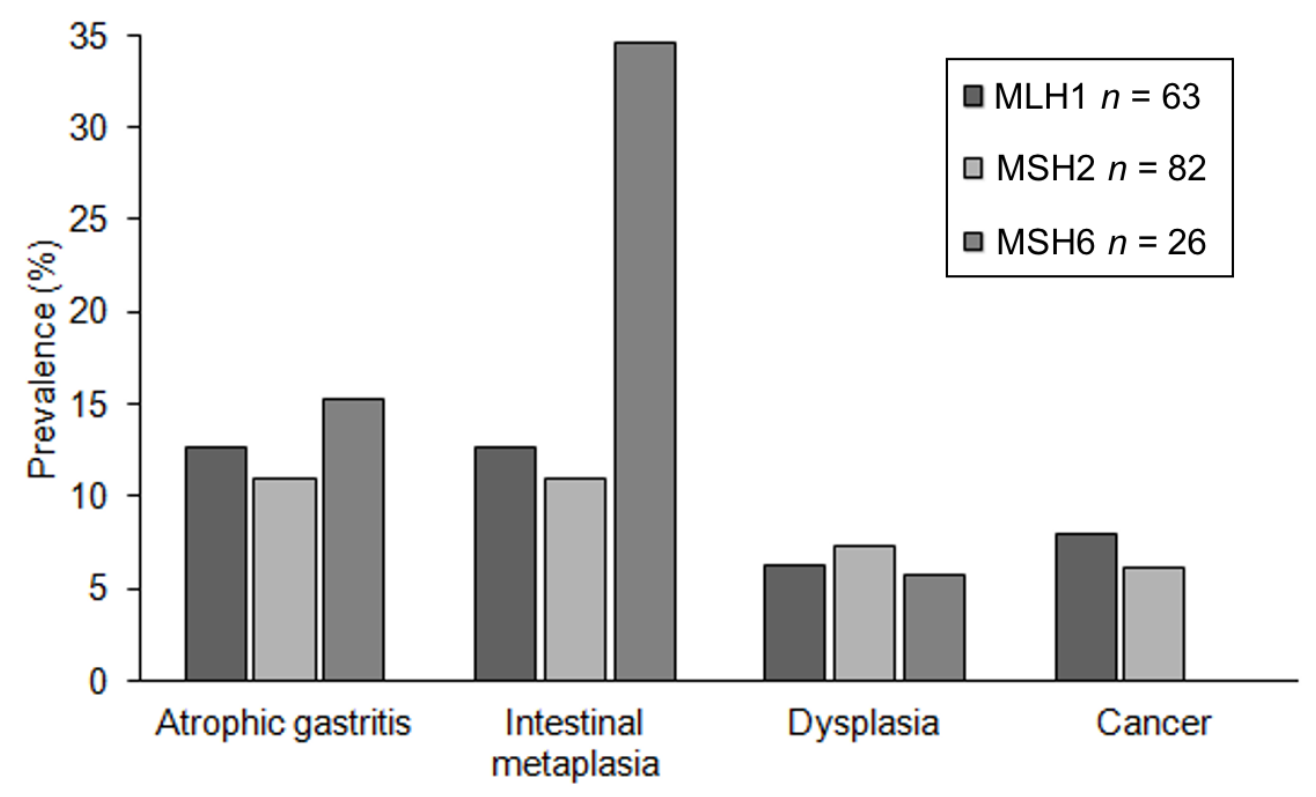

Figure 2. Prevalence of precancerous lesions and cancer in carriers of the MHL1, MSH2, and MSH6 mutations.

Table 4. The characteristics of patients with adenocarcinoma in our study.

\begin{tabular}{|c|c|c|c|}
\hline Characteristics & $\begin{array}{l}\text { Patients with } \\
\text { MLH1 Mutation } \\
\quad(n=5)\end{array}$ & $\begin{array}{l}\text { Patients with } \\
\text { MSH2 Mutation } \\
\quad(n=4)\end{array}$ & $\begin{array}{l}\text { Total Patients with } \\
\text { Adenocarcinomas } \\
\qquad(n=9)\end{array}$ \\
\hline Median age: years (range) & $40(14-54)$ & $51(42-61)$ & $49(14-61)$ \\
\hline \multicolumn{4}{|l|}{ Gender: $n(\%)$} \\
\hline Male & $3(60)$ & $3(75)$ & $6(67)$ \\
\hline Female & $2(40)$ & $1(25)$ & $3(33)$ \\
\hline \multicolumn{4}{|l|}{ Personal history of cancers: } \\
\hline Colorectal cancer & $0(0)$ & $1(25)$ & $1(11)$ \\
\hline Endometrial cancer & $1(20)$ & $1(25)$ & $2(22)$ \\
\hline Urinary tract cancer & $0(0)$ & $1(25)$ & $1(11)$ \\
\hline Diagnosed cancers at initial UGE: $n(\%)$ & $4(80)$ & $3(75)$ & $7(78)$ \\
\hline Digestive symptoms at initial UGE: $n(\%)$ & $3(60)$ & $2(50)$ & $5(63)$ \\
\hline \multicolumn{4}{|l|}{ Tumour localization: n (\%) } \\
\hline Gastric & $2(40)$ & $3(60)$ & $5(50)$ \\
\hline Duodenal & $3(60)$ & $2(40)$ & $5(50)$ \\
\hline \multicolumn{4}{|l|}{ Differentiation grade: $n(\%)$} \\
\hline Well & 1 & 1 & $2(20)$ \\
\hline Moderate & 2 & 2 & $4(40)$ \\
\hline Poor & 0 & 0 & $0(0)$ \\
\hline Missing data & 2 & 1 & $3(30)$ \\
\hline \multicolumn{4}{|l|}{ TNM UICC 2016 staging at diagnosis: $n(\%)$} \\
\hline I & 1 & 2 & 3 \\
\hline II or III & 2 & 1 & 3 \\
\hline IV & 1 & 0 & $1(10)$ \\
\hline Lymph node spreading: $n(\%)$ & 2 & 1 & $3(30)$ \\
\hline Curative surgery: $n(\%)$ & $5(100)$ & $3(75)$ & $9(90)$ \\
\hline Helicobacter pylori infection: $n(\%)$ & $1(20)$ & $1(25)$ & $2(22)$ \\
\hline Associated atrophic gastritis & $1(20)$ & $1(25)$ & $2(22)$ \\
\hline
\end{tabular}

\subsection{Helicobacter pylori Infection}

Testing for $H$. pylori was performed in 145 patients $(84 \%)$ by endoscopic biopsies $(n=143)$ or urea breath tests $(n=2)$. H. pylori infection was diagnosed in 41 patients $(28 \%)$. The prevalence of precancerous and cancerous gastric lesions was higher in patients with 
H. pylori infection than in patients without H. pylori infection ( $51 \%$ vs. $13 \%, p<0.001)$. $H$. pylori infection was not detected in any of the patients with precancerous or cancerous duodenal lesions. The prevalence of $H$. pylori did not differ significantly according to the type of MMR gene mutation. H. pylori infection was found in four of the five cases of gastric dysplasia diagnosed during surveillance, two of which had failed to respond to prior treatments intended to eradicate it.

\section{Discussion}

To the best of our knowledge, this is one of the largest studies to have assessed the prevalence and incidence of neoplastic lesions in individuals with Lynch syndrome enrolled in UGE screening programs. We found that the prevalence of gastroduodenal precancerous and cancerous lesions was high, which increased after 40 years and with $H$. pylori infection, but not with a family history of gastric or duodenal cancer. The results of our study suggest that individuals with Lynch syndrome should be considered for UGE screening, including gastric biopsies in order to check for preneoplastic lesions and H. pylori infection.

The link between Lynch syndrome and upper gastrointestinal cancer risk has been recognized for a long time. In spite of this longstanding association, there have been minimal data to date regarding the patient-specific factors that predict gastric cancer and duodenal cancer among Lynch syndrome carriers. Data from the multinational Prospective Lynch syndrome Database have suggested that older Lynch syndrome carriers with pathogenic MLH1 or MSH2 mutations are at particular risk for upper gastrointestinal cancers, with such individuals having a $7.1 \%$ and $7.7 \%$ cumulative risk of gastric cancer by age 75 , respectively, with a $61 \% 5$-year survival rate [7]. Other prior data have demonstrated that MLH1 and MSH2 carriers, especially males, are at higher risk for gastric cancer than female Lynch syndrome carriers and those with germline mutations in other Lynch syndrome genes $[5,6,8]$. The risk of duodenal carcinoma was reported to be the highest for the MLH1 pathogenic variant carriers (6.5\% for MLH1 and 2\% for MSH2), and no small bowel cancers were observed in patients with the constitutional MSH6 or PMS2 pathogenic variants [7]. Although nearly the majority of guidelines recommend considering an UGE with testing and treatment for H. pylori, the target Lynch syndrome population for screening, the age to begin UGE, and intervals for UGE follow-up are not consistent (Table 1). Because of a paucity of data, there is no concordance among the guidelines on which individuals with Lynch syndrome are most likely to benefit from screening. Conventional UGE is a minimally invasive procedure that can be performed during the same general anaesthesia that the screening colonoscopy regularly accomplished in Lynch syndrome patients. Despite this fact, there are only few studies that have evaluated the effectiveness of screening and surveillance for upper gastrointestinal cancer in these patients.

Lynch syndrome-related colon cancers appear to follow an accelerated colonic adenomacarcinoma sequence [29]. Lynch syndrome-related upper gastrointestinal cancers could result from a similar sequence, with accelerated progression of dysplasia to cancer. The majority of gastric cancers in Lynch syndrome patients appear to be histologically classified as the intestinal type and, consequently, potentially amenable to endoscopic surveillance [5,22]. Lynch syndrome patients develop rare gastric adenomatous polyps compared to patients with familial adenomatous polyposis or MYH associated polyposis. In these latter hereditary syndromes, fundic gland polyp is the most common gastric abnormality. It can develop dysplasia and rarely into invasive adenocarcinoma. In Lynch syndrome, no clear specific polypoid precancerous pattern has been described even though it has been suggested that pyloric gland adenomas may be precursors of gastric cancer [30]. In a young cohort of Lynch syndrome patients, chronic immune gastritis was observed in over $70 \%$ of cases with gastric cancer and none of the patients without gastric cancer [31]. H. pylori infection has been reported in about $20 \%$ of gastric cancers in Lynch syndrome, which is in adequation with our study $[22,32]$. These findings suggest that an evaluation for underlying chronic gastritis as well as $H$. pylori infection should be considered in surveillance protocols for younger individuals with Lynch syndrome. The prevalence of atrophic gastritis and intesti- 
nal metaplasia in our study was in accordance with a previous study by Renkonen et al., reporting a prevalence of $14 \%$ [23]. However, we found 10 cases of cancer and 13 cases of low- or high-grade dysplasia, $80 \%$ and $54 \%$ of which, respectively, were detected at the first endoscopic exam, versus one case of duodenal cancer and no case of dysplastic lesion in this previous study. This difference may be explained by the fact that our study included patients who already had digestive symptoms, as was the case for six out of the nine patients with cancer. Moreover, the study by Renkonen et al. included 73 patients who had undergone endoscopic examination only once and may therefore have underestimated the frequency of neoplastic lesions. Another small, retrospective, single-institution study of 66 LS carriers (21 of whom underwent EGD surveillance) found that 19\% of the screened individuals had potential precursor findings on UGE (H. pylori, intestinal metaplasia) [24]. Our results are contrary to a more recent single-institution cohort of 217 LS carriers whom underwent UGE surveillance, where the prevalence of gastric intestinal metaplasia was low $(8.3 \%)$ [26]. The prevalence of $H$. pylori infection was $28 \%$ in our cohort, which is consistent with the usual prevalence in Europe (around 30\%) [33]. In our study, the prevalence of gastric precancerous lesions and cancer was significantly higher in patients with $H$. pylori infection $(51 \%$ vs. $13 \%, p<0.001)$. Our results indicate that surveillance programs in Lynch syndrome carriers should include investigation of H. pylori infection. As in previous studies, we found no significant difference between MLH1 and MSH2 mutation carriers $[5,34]$. In contrast, the prevalence of intestinal metaplasia was significantly higher in MSH6 mutation carriers than in MLH1 or MSH2 carriers. This difference was not related to the corresponding variation in the prevalence of $H$. pylori infection, which was similar in carriers of the different mutations. The reasons for such a difference (which need to be confirmed by further studies) are unclear. Although some experts propose an endoscopy if more than one family member have gastric cancer, there is no clear evidence that a family history indicates a predisposition in Western countries [2,5]. In a German cohort study of 988 individuals with Lynch syndrome, only one-quarter of patients with gastric cancer had a family history of gastric cancer [34]. A recent study reported that the reported number of first-degree relatives with gastric cancer were independently associated with a reported personal history of gastric cancer in Lynch syndrome patients [35]. In our study, there was no difference in the prevalence of gastroduodenal precancerous lesions or cancers related to family history.

The effectiveness of surveillance using UGE in patients with Lynch syndrome remains controversial, and the recommendation varies among regions [36]. One of the reasons for the controversy is the geographical variation of gastric cancer incidence. As in sporadic cases, the incidence of gastric cancer in Lynch syndrome is higher in Asian countries (up to 40\%) compared with in Western countries (ranging from 1 to 10\%) [4,5,7,36-39]. Based on these reports, environmental factors and particularly $H$. pylori infection act as risk factors for gastric cancer. In 2015, the worldwide prevalence for H. pylori infection was 4.4 billion individuals, with a wide disparity according to geographic regions [40]. In sporadic cases, $H$. pylori is the main cause for chronic gastritis and the main etiological agent for peptic ulcer disease and gastric cancer [41,42]. These clinical outcomes result in a complex multifactorial interplay between bacterial virulence, host immune response, and microbiota modifications [43]. Approximately $89 \%$ of all gastric cancers can be attributable to H. pylori infection [44]. For these reasons, H. pylori has been identified as a Group 1 carcinogen by the International Agency for Research on Cancer and is considered a necessary but insufficient cause of gastric adenocarcinoma. According to Soer et al., it seems that the prevalence of $H$. pylori infection rates in Lynch syndrome mutations carriers does not differ from the general population [32]. Based on these reports, H. pylori infection significantly affects gastric cancer risks in patients with Lynch syndrome. Its eradication is a public health issue of main interest needing more efficient screening and therapeutic strategies. A major hurdle to eradication is increasing antibiotic resistance [45]. To that concern, clear guidelines for the evaluation and treatment of $H$. pylori infection must be regularly put up to date [45]. In our study, the only two patients diagnosed with gastric 
adenocarcinoma and H. pylori infection were also the only ones presenting atrophic gastritis. Patients with Lynch syndrome, particularly those with atrophic gastritis, are at high risk of gastric dysplasia and cancer, and the occurrence of synchronous and/or metachronous multiple lesions is common [46]. Some reports suggested that endoscopic surveillance of Lynch syndrome patients for gastric cancer should be provided based on the estimated risk in each patient $[7,13]$. In our study, most of the patients underwent upper gastrointestinal endoscopy concomitantly with colonoscopy at 1 - to 2-year intervals. However, there is no consensus about the appropriate screening for upper gastrointestinal cancer in Lynch syndrome (Table 1). Guidelines are all based on imprecise or small-sized epidemiological studies, due to the lack of UGE surveillance studies [24-26]. Nevertheless, Capelle et al. have reported that, in a large Dutch cohort of individuals with Lynch syndrome, gastric cancer cases were mostly diagnosed after 45 years and that a family history of gastric cancer was a poor prognosticator of an increase in individual risk [5]. They therefore suggested starting gastric surveillance at 45 years of age, regardless of family history. In our study, however, some precancerous lesions were detected during the third decade of life. The clinical benefit of screening Lynch syndrome patients with gastroscopy probably exists. The decrease in annual incidence and relative proportion for gastric cancer in the general population in later Lynch generations raises the issue of the value of UGE screening in Lynch families [47,48]. A recent large study supports the recommendations of regular UGE surveillance for Lynch syndrome patients. In a prospective, multicentre cohort study of 1128 Lynch syndrome patients, gastric cancers in patients undergoing regular UGE every $1-3$ years were significantly diagnosed, and this more often in an early stage of disease than gastric cancers detected through symptoms ( $83 \%$ vs. $25 \%$ ) [27]. The limited data on the efficacy of UGE screening is a real-world clinical dilemma for Lynch syndrome-associated upper gastrointestinal cancers. We therefore suggest that an initial UGE with systematic gastric biopsies should be performed when Lynch syndrome is diagnosed in order to check for gastric or duodenal precancerous lesions and H. pylori infection. Our results do not support a systematic policy of examinations at 1- to 2-year intervals for upper gastrointestinal endoscopy for all individuals with Lynch syndrome. Firstly, the risk of gastric cancer seems to be low if no precancerous lesion or H. pylori infection is detected by the first endoscopy. Secondly, $70 \%$ of patients with endoscopic surveillance did not go on to develop precancerous lesions or cancer. Endoscopic surveillance might therefore be offered to individuals with precancerous lesions detected at their first endoscopy. Even if the first endoscopy is normal, it seems reasonable to offer endoscopy after the age of 40 years as the risk of cancer increases after this age.

Screening for small-bowel cancer is currently not recommended. Studies of small bowel screening in Lynch syndrome patients are lacking. A recent study suggests regular duodenal screening during UGE, especially in $\mathrm{MSH} 2$ patients [25]. Since half the cases of small-bowel cancer in their cohort occurred in the duodenum, Schulmann et al. suggested adding UGE or push enteroscopy to screening colonoscopy in individuals with Lynch syndrome after the age of 30 years [11]. Guidelines do not recommend surveillance for small bowel cancer by videocapsule or enteroscopy but do suggest inspecting the distal duodenum during UEG if this is performed.

Our study has some limitations, including that our relatively small sample size limits the capacity to detect risk factors among patient with developed upper gastrointestinal cancer and to identify an optimal UGE screening interval. There also might be a bias in our study population. Universal tumour testing for Lynch syndrome revealed that MSH6 and PMS2 carriers are more frequent than previously recognized [49]. Most of the registered Lynch syndrome patients in our study were MLH1 and MSH2 carriers, which are potentially at high risk of Lynch syndrome-associated cancers [8]. Thus, we cannot exclude the possibility of overestimation of upper gastrointestinal cancer risk compared with the genuine Lynch syndrome population. Information on H. pylori status and histological assessment of gastric mucosa metaplasia was not available for all patients. However, both endoscopic findings of gastric atrophy and histological assessment of intestinal metaplasia 
were reported to be an accurate alternative for atrophic gastritis with excellent interobserver agreement [50,51]. As atrophic gastritis has been reported to be strongly associated with H. pylori, we consider that the endoscopic and histological findings can be a good substitute for $H$. pylori status in clinical settings [52]. Our findings underline the crucial need for future larger collaborative studies involving healthcare networks specialized in Lynch Syndrome management to scrutinise this issue.

\section{Conclusions}

In conclusion, our study may help to work out an appropriate screening program for gastric and duodenal cancer in individuals with Lynch syndrome. We show that the incidence of gastroduodenal precancerous lesions and cancers increased significantly after 40 years and was associated in more than $50 \%$ of patients with $H$. pylori infection. Nevertheless, the incidence of dysplastic lesions and cancer was low during endoscopic follow-up. Although we emphasize that our data are insufficient to justify a specific approach to UGE screening, we suggest a first UGE in all patients with Lynch syndrome with systematic gastric biopsies to check for precancerous lesions and screening for H. pylori infection, regardless of the type of MMR gene mutation or any family history of gastroduodenal cancer. During follow-up, UGE could be offered to all Lynch syndrome patients with a nonPMS2 mutation, a family history of upper gastrointestinal cancer, or upper gastrointestinal precursor lesions such as gastric atrophy, autoimmune gastritis, intestinal neoplasia, or duodenal adenoma, while recognizing the limitations of the current evidence. Future studies should assess the effectiveness and cost-effectiveness of periodic (e.g., biennial) UGE surveillance for patients with precancerous lesions at the first endoscopy and for individuals over 40 years or with others risk factors, and whether longer surveillance intervals could be safe in other individuals with Lynch syndrome.

Author Contributions: Conceptualization, T.L. and S.F.; methodology, T.L. and S.F.; formal analysis, T.L., S.F. and R.C.; investigation, R.C., D.M., E.S., D.T., D.B., O.C., G.R., T.B., C.C., S.F. and T.L.; writing, T.L., S.F. and R.C. All authors have read and agreed to the published version of the manuscript.

Funding: This research received no external funding.

Institutional Review Board Statement: The study was conducted according to the guidelines of the Declaration of Helsinki, and approved by Ethics Committee of Human Research of Trousseau University Hospital, CHU de Tours, CEDEX 09, 37044 Tours, France (protocol code 2021 004, 20/04/2021).

Informed Consent Statement: Informed consent was obtained from all subjects involved in the study.

Data Availability Statement: The data presented in this study are available on request from the corresponding author.

Conflicts of Interest: The authors declare no conflict of interest.

\section{References}

1. Lynch, H.T.; De la Chapelle, A. Hereditary colorectal cancer. N. Engl. J. Med. 2003, 348, 919-932. [CrossRef] [PubMed]

2. Watson, P.; Vasen, H.F.A.; Mecklin, J.P.; Bernstein, I.; Aarnio, M.; Järvinen, H.J.; Myrhøj, T.; Sunde, L.; Wijnen, J.T.; Lynch, H.T. The risk of extra-colonic, extra-endometrial cancer in the Lynch syndrome. Int. J. Cancer. 2008, 123, 444-449. [CrossRef]

3. de Leon, M.P.; Pedroni, M.; Benatti, P.; Percesepe, A.; Di Gregorio, C.; Foroni, M.; Rossi, G.; Genuardi, M.; Neri, G.; Leonardi, F.; et al. Hereditary colorectal cancer in the general population: From cancer registration to molecular diagnosis. Gut 1999, 45, 32-38. [CrossRef] [PubMed]

4. Tafe, L.J.; Riggs, E.R.; Tsongalis, G.J. Lynch syndrome presenting as endometrial cancer. Clin. Chem. 2014, 60, 111-121. [CrossRef]

5. Capelle, L.G.; Van Grieken, N.C.; Lingsma, H.F.; Steyerberg, E.W.; Klokman, W.J.; Bruno, M.J.; Vasen, H.F.; Kuipers, E.J. Risk and epidemiological time trends of gastric cancer in Lynch syndrome carriers in the Netherlands. Gastroenterology 2010, 138, 487-492. [CrossRef] [PubMed]

6. $\quad$ Engel, C.; Loeffler, M.; Steinke, V.; Rahner, N.; Holinski-Feder, E.; Dietmaier, W.; Schackert, H.K.; Goergens, H.; von Knebel Doeberitz, M.; Goecke, T.O.; et al. Risks of less common cancers in proven mutation carriers with lynch syndrome. J. Clin. Oncol. 2012, 30, 4409-4415. [CrossRef] [PubMed] 
7. Møller, P.; Seppälä, T.T.; Bernstein, I.; Holinski-Feder, E.; Sala, P.; Gareth Evans, D.; Lindblom, A.; Macrae, F.; Blanco, I.; Sijmons, R.H.; et al. Cancer risk and survival in path_MMR carriers by gene and gender up to 75 years of age: A report from the Prospective Lynch Syndrome Database. Gut 2018, 67, 1306-1316. [CrossRef]

8. Bonadona, V.; Bonaïti, B.; Olschwang, S.; Grandjouan, S.; Huiart, L.; Longy, M.; Guimbaud, R.; Buecher, B.; Bignon, Y.J.; Caron, O.; et al. Cancer Risks Associated with Germline Mutations in MLH1, MSH2, and MSH6 Genes in Lynch Syndrome. JAMA 2011, 305, 2304-2310. [CrossRef]

9. Schulmann, K.; Brasch, F.E.; Kunstmann, E.; Engel, C.; Pagenstecher, C.; Vogelsang, H.; Krüger, S.; Vogel, T.; Knaebel, H.P.; Rüschoff, J.; et al. HNPCC-associated small bowel cancer: Clinical and molecular characteristics. Gastroenterology 2005, 128, 590-599. [CrossRef]

10. ten Kate, G.L.; Kleibeuker, J.H.; Nagengast, F.M.; Craanen, M.; Cats, A.; Menko, F.H.; Vasen, H.F.A. Is surveillance of the small bowel indicated for Lynch syndrome families? Gut 2007, 56, 1198-1201. [CrossRef]

11. Schulmann, K.; Engel, C.; Propping, P.; Schmiegel, W. Small bowel cancer risk in Lynch syndrome. Gut 2008, 57, 1629-1630. [CrossRef] [PubMed]

12. Järvinen, H.J.; Aarnio, M.; Mustonen, H.; Aktan-Collan, K.; Aaltonen, L.A.; Peltomäki, P.; De La Chapelle, A.; Mecklin, J.P. Controlled 15-year trial on screening for colorectal cancer in families with hereditary nonpolyposis colorectal cancer. Gastroenterology 2000, 118, 829-834. [CrossRef]

13. Giardiello, F.M.; Allen, J.I.; Axilbund, J.E.; Boland, C.R.; Burke, C.A.; Burt, R.W.; Church, J.M.; Dominitz, J.A.; Johnson, D.A.; Kaltenbach, T.; et al. Guidelines on genetic evaluation and management of Lynch syndrome: A consensus statement by the US Multi-Society Task Force on colorectal cancer. Gastroenterology 2014, 147, 502-526. [CrossRef] [PubMed]

14. Seppälä, T.T.; Latchford, A.; Negoi, I.; Sampaio Soares, A.; Jimenez-Rodriguez, R.; Sánchez-Guillén, L.; Evans, D.G.; Ryan, N.; Crosbie, E.J.; Dominguez-Valentin, M.; et al. European guidelines from the EHTG and ESCP for Lynch syndrome: An updated third edition of the Mallorca guidelines based on gene and gender. Br. J. Surg. 2020. [CrossRef]

15. Syngal, S.; Brand, R.E.; Church, J.M.; Giardiello, F.M.; Hampel, H.L.; Burt, R.W. American College of Gastroenterology. ACG clinical guideline: Genetic testing and management of hereditary gastrointestinal cancer syndromes. Am. J. Gastroenterol. 2015, 110, 223-262. [CrossRef]

16. Stoffel, E.M.; Mangu, P.B.; Gruber, S.B.; Hamilton, S.R.; Kalady, M.F.; Lau, M.W.; Lu, K.H.; Roach, N.; Limburg, P.J.; American Society of Clinical Oncology; et al. Hereditary colorectal cancer syndromes: American Society of Clinical Oncology Clinical Practice Guideline endorsement of the familial risk colorectal cancer: European Society for Medical Oncology Clinical Practice Guidelines. J. Clin. Oncol. 2015, 33, 209-217. [CrossRef]

17. Vangala, D.B.; Cauchin, E.; Balmaña, J.; Wyrwicz, L.; van Cutsem, E.; Güller, U.; Castells, A.; Carneiro, F.; Hammel, P.; Ducreux, M.; et al. Screening and surveillance in hereditary gastrointestinal cancers: Recommendations from the European Society of Digestive Oncology (ESDO) expert discussion at the 20th European Society for Medical Oncology (ESMO)/World Congress on Gastrointestinal Cancer, Barcelona, June 2018. Eur. J. Cancer 2018, 104, 91-103.

18. Monahan, K.J.; Bradshaw, N.; Dolwani, S.; Desouza, B.; Dunlop, M.G.; East, J.E.; Ilyas, M.; Kaur, A.; Lalloo, F.; Latchford, A.; et al. Guidelines for the management of hereditary colorectal cancer from the British Society of Gastroenterology (BSG)/Association of Coloproctology of Great Britain and Ireland (ACPGBI)/United Kingdom Cancer Genetics Group (UKCGG). Gut 2020, 69, 411-444. [CrossRef]

19. Ley, C.; Parsonnet, J. Helicobacter pylori infection and gastric cancer. Gastroenterology 2001, 120, 324-325. [CrossRef]

20. Correa, P.; Houghton, J. Carcinogenesis of Helicobacter pylori. Gastroenterology 2007, 133, 659-672. [CrossRef]

21. Malfertheiner, P.; Megraud, F.; O’Morain, C.A.; Gisbert, J.P.; Kuipers, E.J.; Axon, A.T.; Bazzoli, F.; Gasbarrini, A.; Atherton, J.; Graham, D.Y.; et al. Management of Helicobacter pylori infection-the Maastricht V/Florence Consensus Report. Gut 2017, 66, 6-30. [CrossRef] [PubMed]

22. Aarnio, M.; Salovaara, R.; Aaltonen, L.A.; Mecklin, J.P.; Järvinen, H.J. Features of gastric cancer in hereditary non-polyposis colorectal cancer syndrome. Int. J. Cancer 1997, 74, 551-555. [CrossRef]

23. Renkonen-Sinisalo, L.; Sipponen, P.; Aarnio, M.; Julkunen, R.; Aaltonen, L.A.; Sarna, S.; Järvinen, H.J.; Mecklin, J.P. No support for endoscopic surveillance for gastric cancer in hereditary non-polyposis colorectal cancer. Scand. J. Gastroenterol. 2002, 37, 574-577. [CrossRef] [PubMed]

24. Galiatsatos, P.; Labos, C.; Jeanjean, M.; Miller, K.; Foulkes, W.D. Low yield of gastroscopy in patients with Lynch syndrome. Turk. J. Gastroenterol. 2017, 28, 434-438. [CrossRef] [PubMed]

25. Hammoudi, N.; Dhooge, M.; Coriat, R.; Leblanc, S.; Barret, M.; Bordacahar, B.; Beuvon, F.; Prat, F.; Maksimovic, F.; Chaussade, S. Duodenal tumor risk in Lynch syndrome. Dig. Liver Dis. 2019, 51, 299-303. [CrossRef] [PubMed]

26. Kumar, S.; Dudzik, C.M.; Reed, M.; Long, J.M.; Wangensteen, K.J.; Katona, B.W. Upper Endoscopic Surveillance in Lynch Syndrome Detects Gastric and Duodenal Adenocarcinomas. Cancer Prev. Res. 2020, 13, 1047-1054. [CrossRef]

27. Ladigan-Badura, S.; Vangala, D.B.; Engel, C.; Bucksch, K.; Hueneburg, R.; Perne, C.; German Consortium for Familial Intestinal Cancer. Value of upper gastrointestinal endoscopy for gastric cancer surveillance in patients with Lynch syndrome. Int. J. Cancer 2021, 148, 106-114. [CrossRef]

28. Dixon, M.F.; Genta, R.M.; Yardley, J.H.; Correa, P. Classification and grading of gastritis. The updated Sydney System. International Workshop on the Histopathology of Gastritis, Houston 1994. Am. J. Surg. Pathol. 1996, 20, 1161-1181. [CrossRef] 
29. De Jong, A.E.; Morreau, H.; Van Puijenbroek, M.; Eilers, P.H.; Wijnen, J.; Nagengast, F.M.; Griffioen, G.; Cats, A.; Menko, F.H.; Kleibeuker, J.H.; et al. The role of mismatch repair gene defects in the development of adenomas in patients with HNPCC. Gastroenterology 2004, 126, 42-48. [CrossRef]

30. Brosens, L.A.; Giardiello, F.M.; Offerhaus, G.J.; Montgomery, E.A. Syndromic Gastric Polyps: At the Crossroads of Genetic and Environmental Cancer Predisposition. Adv. Exp. Med. Biol. 2016, 908, 347-369.

31. Adar, T.; Friedman, M.; Rodgers, L.H.; Shannon, K.M.; Zukerberg, L.R.; Chung, D.C. Gastric cancer in Lynch syndrome is associated with underlying immune gastritis. J. Med. Genet. 2019, 56, 844-845. [CrossRef]

32. Soer, E.C.; Leicher, L.W.; Langers, A.M.; van de Meeberg, P.C.; van der Wouden, E.J.; Koornstra, J.J.; Bigirwamungu-Bargeman, M.; Vasen, H.F.; de Vos tot Nederveen Cappel, W.H. Equivalent Helicobacter pylori infection rates in Lynch syndrome mutation carriers with and without a first-degree relative with gastric cancer. Int. J. Colorectal. Dis. 2016, 31, 693-697. [CrossRef] [PubMed]

33. Ford, A.C.; Axon, A.T.R. Epidemiology of Helicobacter pylori infection and public health implications. Helicobacter 2010, 15, 1-6. [CrossRef] [PubMed]

34. Goecke, T.; Schulmann, K.; Engel, C.; Holinski-Feder, E.; Pagenstecher, C.; Schackert, H.K.; Kloor, M.; Kunstmann, E.; Vogelsang, H.; Keller, G.; et al. Genotype-phenotype comparison of German MLH1 and MSH2 mutation carriers clinically affected with Lynch syndrome: A report by the German HNPCC Consortium. J. Clin. Oncol 2006, 24, 4285-4292. [CrossRef] [PubMed]

35. Kim, J.; Braun, D.; Ukaegbu, C.; Dhingra, T.G.; Kastrinos, F.; Parmigiani, G.; Syngal, S.; Yurgelun, M.B. Clinical Factors Associated with Gastric Cancer in Individuals with Lynch Syndrome. Clin. Gastroenterol. Hepatol. 2020, 18, 830-837. [CrossRef] [PubMed]

36. Pan, J.Y.; Haile, R.W.; Templeton, A.; Macrae, F.; Qin, F.; Sundaram, V.; Ladabaum, U. Worldwide practice patterns in Lynch syndrome diagnosis and management, based on data from the international mismatch repair consortium. Clin. Gastroenterol. Hepatol. 2018, 16, 1901-1910. [CrossRef]

37. Park, Y.J.; Shin, K.H.; Park, J.G. Risk of gastric cancer in hereditary nonpolyposis colorectal cancer in Korea. Clin. Cancer Res. 2000, 6, 2994-2998.

38. Saita, C.; Yamaguchi, T.; Horiguchi, S.I.; Yamada, R.; Takao, M.; Iijima, T.; Wakaume, R.; Aruga, T.; Tabata, T.; Koizumi, K. Tumor development in Japanese patients with Lynch syndrome. PLoS ONE 2018, 3, e0195572. [CrossRef] [PubMed]

39. Ikenoue, T.; Arai, M.; Ishioka, C.; Iwama, T.; Kaneko, S.; Matsubara, N.; Moriya, Y.; Nomizu, T.; Sugano, K.; Tamura, K.; et al. Importance of gastric cancer for the diagnosis and surveillance of Japanese Lynch syndrome patients. J. Hum. Genet. 2019, 64, 1187-1194. [CrossRef]

40. Hooi, J.K.Y.; Lai, W.Y.; Ng, W.K.; Suen, M.M.Y.; Underwood, F.E.; Tanyingoh, D.; Malfertheiner, P.; Graham, D.Y.; Wong, V.W.S.; Wu, J.C.Y.; et al. Global Prevalence of Helicobacter pylori Infection: Systematic Review and Meta Analysis. Gastroenterology 2017, 153, 420-429. [CrossRef]

41. Wang, C.; Yuan, Y.; Hunt, R.H. The association between Helicobacter pylori infection and early gastric cancer: A meta-analysis. Am. J. Gastroenterol. 2007, 102, 1789-1798.

42. Malfertheiner, P.; Megraud, F.; O’Morain, C.; Malfertheiner, P.; Megraud, F.; O’Morain, C.; Bazzoli, F.; El-Omar, E.; Graham, D.; Hunt, R.; et al. Current concepts in the management of Helicobacter pylori infection: The Maastricht III Consensus Report. Gut 2007, 56, 772-781. [CrossRef]

43. Wroblewski, L.E.; Peek, R.M. Helicobacter pylori, Cancer, and the Gastric Microbiota. In Advances in Experimental Medicine and Biology; Jansen, M., Wright, N., Eds.; Stem Cells, Pre-neoplasia, and Early Cancer of the Upper Gastrointestinal Tract; Springer: Berlin/Heidelberg, Germany, 2016; Volume 908.

44. IARC Helicobacter Pylori Working Group. Helicobacter Pylori Eradication as a Strategy for Preventing Gastric Cancer. Lyon, France: International Agency for Research on Cancer (IARC Working Group Reports, No. 8). 2014. Available online: http: //www.iarc.fr/en/publications/pdfsonline/wrk/wrk8/index.php (accessed on 2 February 2021).

45. Crowe, S.E. Helicobacter pylori Infection. N. Engl. J. Med. 2019, 380, 1158-1165. [CrossRef]

46. Cho, H.; Yamada, M.; Sekine, S.; Tanabe, N.; Ushiama, M.; Hirata, M.; Ogawa, G.; Gotoh, M.; Yoshida, T.; Yoshikawa, T.; et al. Gastric cancer is highly prevalent in Lynch syndrome patients with atrophic gastritis. Gastric Cancer 2020, 1-9. [CrossRef] [PubMed]

47. Barrow, E.; Robinson, L.; Alduaij, W.; Shenton, A.; Clancy, T.; Lalloo, F.; Hill, J.; Evans, D.G. Cumulative lifetime incidence of extracolonic cancers in Lynch syndrome: A report of 121 families with proven mutations. Clin. Genet. 2009, 75, 141-149. [CrossRef] [PubMed]

48. Karimi, M.; von Salomé, J.; Aravidis, C.; Silander, G.; Askmalm, M.S.; Henriksson, I.; Gebre-Medhin, S.; Frödin, J.E.; Björck, E.; Lagerstedt-Robinson, K.; et al. A retrospective study of extracolonic, non-endometrial cancer in Swedish Lynch syndrome families. Hered Cancer Clin. Pract. 2018, 23, 16. [CrossRef]

49. Espenschied, C.R.; LaDuca, H.; Li, S.; McFarland, R.; Gau, C.L.; Hampel, H. Multigene panel testing provides a new perspective on Lynch syndrome. J. Clin. Oncol. 2017, 35, 2568-2575. [CrossRef]

50. Watanabe, K.; Nagata, N.; Nakashima, R.; Furuhata, E.; Shimbo, T.; Kobayakawa, M.; Sakurai, T.; Imbe, K.; Niikura, R.; Yokoi, C.; et al. Predictive findings for helicobacter pylori uninfected,-infected and-eradicated gastric mucosa: Validation study. World $J$. Gastroenterol. 2013, 19, 4374-4379. [CrossRef] 
51. Capelle, L.G.; de Vries, A.C.; Haringsma, J.; Ter Borg, F.; de Vries, R.A.; Bruno, M.J.; van Dekken, H.; Meijer, J.; van Grieken, N.C.; Kuipers, E.J. The staging of gastritis with the OLGA system by using intestinal metaplasia as an accurate alternative for atrophic gastritis. Gastrointest. Endosc. 2010, 71, 1150-1158. [CrossRef]

52. Asaka, M.; Sugiyama, T.; Nobuta, A.; Kato, M.; Takeda, H.; Graham, D.Y. Atrophic gastritis and intestinal metaplasia in Japan: Results of a large multicenter study. Helicobacter 2001, 6, 294-299. [CrossRef] 